\title{
Article \\ Bimetallic Copper-Silver Systems Supported on Natural Clinoptilolite: Long-Term Changes in Nanospecies' Composition and Stability
}

\author{
Inocente Rodríguez-Iznaga ${ }^{1, * \mathbb{D}}$, Vitalii Petranovskii ${ }^{2, *(\mathbb{D})}$, Fernando Chávez-Rivas ${ }^{3} \mathbb{D}$ and \\ Marina G. Shelyapina 4 (iD) \\ 1 Instituto de Ciencias y Tecnología de Materiales (IMRE), Universidad de La Habana, Zapata y G, s/n, \\ La Havana 10400, Cuba \\ 2 Centro de Nanociencias y Nanotecnología $(\mathrm{CNyN})$, Universidad Nacional Autónoma de México, \\ Carretera Tijuana-Ensenada, Km 107, Ensenada 22860, Mexico \\ 3 Escuela Superior de Física y Matemáticas, Instituto Politécnico Nacional (IPN), Mexico City 07738, Mexico; \\ fchavezrivas5@gmail.com \\ 4 Faculty of Physics, Saint-Petersburg State University, 7/9 Universitetskaya nab., 199034 St. Petersburg, Russia; \\ marina.shelyapina@spbu.ru \\ * Correspondence: inocente@imre.uh.cu (I.R.-I.); vitalii@cnyn.unam.mx (V.P.)
}

check for

updates

Citation: Rodríguez-Iznaga, I.;

Petranovskii, V.; Chávez-Rivas, F.; Shelyapina, M.G. Bimetallic Copper-Silver Systems Supported on Natural Clinoptilolite: Long-Term Changes in Nanospecies' Composition and Stability. Inorganics 2022, 10, 34. https://doi.org/ 10.3390 /inorganics 10030034

Academic Editor: Antonino Gulino

Received: 24 January 2022

Accepted: 27 February 2022

Published: 4 March 2022

Publisher's Note: MDPI stays neutral with regard to jurisdictional claims in published maps and institutional affiliations.

Copyright: (C) 2022 by the authors. Licensee MDPI, Basel, Switzerland. This article is an open access article distributed under the terms and conditions of the Creative Commons Attribution (CC BY) license (https:// creativecommons.org/licenses/by/ $4.0 /)$.

\begin{abstract}
Long-term changes in species of copper-silver bimetallic systems on natural clinoptilolite obtained by ion exchange of $\mathrm{Cu}^{2+}$ and $\mathrm{Ag}^{+}$and then reduced at different temperatures were studied. Even after storage under ambient conditions, XRD and UV-Vis diffuse reflectance spectra indicate the presence of nanospecies and larger particles of reduced copper and silver. Scanning electron microscopy of aged bimetallic samples, reduced at the highest temperature $\left(450^{\circ} \mathrm{C}\right)$ and the pristine sample for their preparation, also aged, showed the presence of silver particles with a size of about $100 \mathrm{~nm}$. They are formed in the initial ion-exchanged sample (without reduction) due to the degradation of $\mathrm{Ag}^{+}$ions. The particles in the reduced sample are larger; in both samples they are evenly distributed over the surface. The presence of silver affects the stability and the mechanism of decomposition/oxidation of reduced copper species, and this stability is higher in bimetallic systems. The decomposition pattern of recently reduced species includes the formation of smaller nanoparticles and few-atomic clusters. This can occur, preceding the complete oxidation of $\mathrm{Cu}$ to ions. Quasicolloidal silver, which is present in fresh bimetallic samples reduced at lower temperatures, transforms after aging into $\mathrm{Ag}_{8}$ clusters, which indicates the stability of these nanospecies on natural clinoptilolite.
\end{abstract}

Keywords: clinoptilolite zeolite; nanospecies; bimetallic system; copper; silver

\section{Introduction}

Several metallic species, such as ions, clusters and nanoparticles, deposited on the surface or entrapped on zeolites and other microporous, mesoporous and nanoporous matrices, are of great interest for the development of nanostructured materials for diverse applications in areas such as catalysis [1-7], water purification [8-12], general medicine [13,14], synthesis of antimicrobial and antifungal materials [15-17] and in a number of other areas [18-23]. The development of packing materials containing zeolites modified with silver, copper and zinc ions and metal nanoparticles, which have antimicrobial and fungicidal properties is reviewed in $[15,20,23]$. A detailed characterization of the $\mathrm{Cu}$ species present in the de- $\mathrm{NO}_{x}$ selective catalytic reduction zeolite-based catalyst undertaken before, during, and after the hydrothermal aging treatment of the material was carried out [24] to study changes in copper species, their location and their stability.

As the properties of copper nanoparticles largely depend on the procedures for their synthesis, the properties of the support, and the interaction with it, the choice of an 
appropriate synthesis method becomes crucial for the success in a particular application. Various methods for the synthesis of copper nanoparticles employing chemical, physical and biological techniques that explore bottom-up and top-down methods of synthesis are described in Ref. [25]. The development of modern methods for designing catalysts, in which nanostructured active centers play a dominant role in determining their efficiency and selectivity, is becoming a key factor in progress in the modification of catalytic materials, such as supported metal nanoparticles.

The approach used in our previous work [26] to the assembly of copper materials integrated at the atomic/molecular level on a zeolite matrix is a variation of the "bottomup" method, which starts with the reduction of copper ions in a hydrogen flow and is accompanied by the agglomeration of atoms (and/or ions) of copper into larger reduced copper species with a high surface area-to-volume ratio and a high concentration of low coordinated sites and surface vacancies. These compounds exist at the boundary between molecular states with discrete quantum energy levels and quasibulk metal nanoparticles. Such a system is often referred to as a "quasihomogeneous system" [6].

New materials for a variety of applications can be designed by using metal nanoparticles and clusters. Their insufficiently high durability is one of the key issues hindering the development of new efficient materials, and the factors affecting the degradation of nanoparticles are not fully understood.

Zeolites are nanostructured materials with regular pores, channels and cavities, which can confine different chemical species in their structure. Particular attention is paid to the stability of the oxidation state and the aggregation degree of such species in connection with their great influence on the quality of the materials being developed.

Numerous approaches have been taken to increase the stability of metal nanoparticles formed during the synthesis. In search of the best method, various stabilizers have been used, such as inorganic salts, organic compounds, organic solvents, biological molecules, etc. The influence of the composition of zeolites, that is, their Si/Al ratio, as well as the influence of other exchangeable counter-cations in a binary or ternary mixture of metal cations over zeolite systems have been widely investigated [26-33].

General pathways for "bottom-up" synthesis of metal nanoparticles are based on chemical reduction of metal precursors in the presence of stabilizing ligands. It is known that such ligands can affect the stability of nanoparticles and their resistance to aggregation. The catalytic activity of catalysts based on nanoparticles often collides with deactivation caused by sintering and/or agglomeration of active particles during catalytic reactions [6].

The results of consideration of intrazeolite reactions according to the host-guests principle make it possible to reckon in the zeolite framework as an analogue of the ligand and consider the concept of "zeolate" as a multidentate anionic ligand. The representation of the zeolite channel as a crystalline ligand makes it possible to use methods of coordination chemistry for understanding the metal-ligand bonds in a variety of "cage compounds" based on zeolite host-guest inclusion systems [34,35].

A comparative study [36] of the formation and stabilization of clusters and nanoparticles of silver and gold in mordenites demonstrated that silver clusters are relatively stable after long-term storage for 6 and 12 months, while the oxidation of gold clusters and nanoparticles by air under the same conditions is probable cause of catalyst deactivation. Gold catalysts supported on several zeolite matrices were also modified with Fe and $\mathrm{Ni}$ [37]. It was shown that the presence of oxide from modifying additives stabilizes fine gold particles and promotes the activation of catalysts at low temperatures, especially in the case of iron. The deposition of gold varieties on $\mathrm{H}^{+}$- and $\mathrm{NH}_{4}{ }^{+}$-mordenites revealed a significant effect on the nature of cations on the size distribution and electronic state of the deposited gold nanoparticles, clusters and cations [36,38]. This effect is not unique only to gold catalysts. It was reported [39] that the introduction of platinum stabilized Pt-Ga alloy particles into zeolite channels and increases the catalytic activity and selectivity of $\mathrm{Pt}-\mathrm{Ga} / \mathrm{ZSM}-5$ in ethane aromatization. A theoretical study on the interaction of $\mathrm{Co}_{6}$ and $\mathrm{Pt}_{6}$ clusters with silicalite ZSM-5 and HZSM-5 indicates that the introduction of cobalt 
or platinum into silicalite slightly stabilizes the metal cluster and causes a small positive charge on the $\mathrm{Co}_{6}$ particle, while lead to a noticeable negative charge on the $\mathrm{Pt}_{6}$ particle [40].

The ability of zeolites modified with copper-containing species (ions, clusters and nanoparticles) to reduce $\mathrm{NO}_{x}$ to $\mathrm{N}_{2}$ stimulates considerable interest to them as catalysts [1,41-43]. One of the limitations for the use of these materials is the low stability of certain types of copper species [24,44], mainly at low levels of aggregation $(\mathrm{nm})$ and certain states of oxidation $(0$ and $1+)$. We paid special attention to the study of copper species deposited on natural and synthetic zeolites in multimetallic systems [4,26,29-32]. It has been shown that the addition of a second metal (for example, $\mathrm{Zn}$ and $\mathrm{Ag}$ ) can significantly affect the stabilization of a certain type of copper species and the degree of aggregation of nanoparticles.

Among the zeolites available on the market, natural ones attract a lot of attention due to their availability, low cost, affinity to cations, etc. Clinoptilolite is a widely used natural zeolite due to its abundance, nontoxic nature and good ion-exchange properties. Thus, the use of natural zeolites to obtain efficient and stable materials with catalytic or antimicrobial properties is a very attractive goal. Among other metals, copper and silver are interesting to modify the natural zeolites in order to obtain different materials with dual biocidal and catalytic properties. Its multimetallic composition will reinforce and increase the spectrum of action of this dual property, up to a level higher than that of a zeolite modified with a single metal due to the synergy of the properties of different nanospecies. Such materials can find a massive use, for example, as powerful antimicrobial additives for building materials for constructions that require protection against pathogenic microorganisms, such as hospital and sanitary units. However, its properties depend on the type, stability and durability of nanospecies supported.

In a previous paper, we reported the results for the $\mathrm{Cu}^{2+}-\mathrm{Ag}^{+}$bimetallic system, first subjected to ion exchange in natural clinoptilolite from the Tasajeras deposit (Cuba), and then thermally reduced in a flow of hydrogen [26]. The results showed a significant mutual influence of both cations during reduction, and the formation of different metallic species for both copper and silver. The reduction of $\mathrm{Cu}^{2+}$ is facilitated by the presence of $\mathrm{Ag}^{+}$, probably due to the formation of silver clusters $\left(\mathrm{Ag}_{\mathrm{m}}\right)$ with a positive charge density, which weakens the interaction of the $\mathrm{Cu}^{2+}$-ion with the zeolite framework, facilitating the copper reduction. The aggregation of both reduced metals in this bimetallic system is limited compared to monometallic systems (Cu-only or Ag-only zeolites). The introduction of a second metal can be an alternative method for controlling the size of the resulting metal nanoparticles. Moreover, the presence of silver promotes copper reduction mainly at low temperatures [26], which can contribute to a decrease in the size of aggregated copper species due to a decrease in the diffusion of the reduced copper atom over the zeolite surface.

The aim of the present work is to study long-term changes in the composition and stability of metal nanospecies obtained by the previously described method in a mixed bimetallic copper-silver system deposited on natural clinoptilolite [26], by analyzing changes in the properties of samples during storage under ambient conditions.

\section{Results and Discussion}

\subsection{UV-Vis Diffuse Reflectance Spectroscopy}

Interpretation of UV-Vis diffuse reflectance spectra for samples supported on natural zeolites is complicated by the fact that natural materials have their own optical absorbance due to the various impurities inherent to minerals. As an example, Figure 1a shows the spectra of natural clinoptilolite (CLI), as well as samples with exchange for Cu and $\mathrm{Cu}-\mathrm{Ag}$. To clarify the current changes in the spectra of the samples during their storage, the spectrum of the initial sample of clinoptilolite was subtracted from the spectra of all samples. This was done to obtain the absorption due to the copper and silver species deposited on the zeolite in the exchanged samples, the result is shown in Figure 1b. The subtracted spectra for all samples reduced at different temperatures are shown in a similar 
way, Figure $2 \mathrm{a}-\mathrm{h}$. In the text and figures, these subtracted spectra, showing absorption due to the difference in the optical density of the spectra of the samples and the spectrum of the clinoptilolite matrix are marked as it was introduced earlier, without reference to their subtractive nature, and we also do not repeat the word "subtracted" while mentioning "spectra" in the text. In order to distinguish the reduced samples, after the metal symbols (with numbers denoting ratios of metals in the exchange solution) and CLI, appear the reduction temperature and the designations $F$ and $A$ for fresh $(F)$ and aged $(A)$ samples, for example, Cu9Ag1CLI-450-F and Cu9Ag1CLI-450-A.
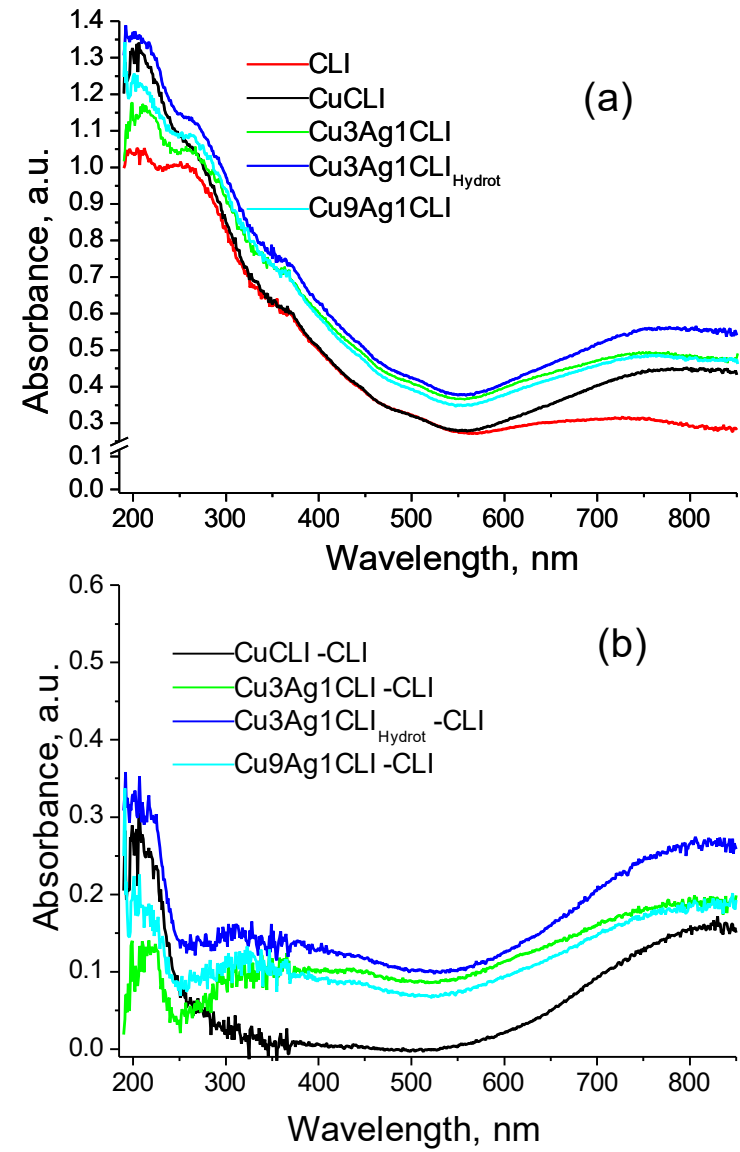

Figure 1. UV-Vis diffuse reflectance spectra of the exchanged mono- and bi-metallic samples (a) and subtracted spectra (b), showing absorption due to $\mathrm{Cu}^{2+}$ ions only. Note that absorbance scale is different for $(\mathbf{a}, \mathbf{b})$.

Two bands associated with $\mathrm{Cu}^{2+}$ ions are observed in the spectrum of the aged monometallic CuCLI-50-A sample reduced at $50{ }^{\circ} \mathrm{C}$ (Figure $2 \mathrm{f}$ ). The first one, centered at $800-850 \mathrm{~nm}$, is assigned to a spin-allowed transition ${ }^{2} \mathrm{E}_{\mathrm{g}} \rightarrow{ }^{2} \mathrm{~T}_{\mathrm{g}}$. The second band, centered at $207 \mathrm{~nm}$ belongs to a charge-transfer complex due to the interaction of $\mathrm{Cu}^{2+}$ with oxygen of the zeolite framework and/or ligand water molecules. Such a charge transfer band is also typical for other $\mathrm{Cu}^{2+}$-exchange zeolites; it is observed in mordenites by XPS and EPR methods $[45,46]$.

Both bands are also present in ion exchanged monometallic and bimetallic samples before reduction (Figure 1b). These results are consistent with those obtained and published [26] for a fresh monometallic CuCLI-50-F sample, reduced at $50{ }^{\circ} \mathrm{C}$ (Figure 2b). The monometallic CuCLI-50-A sample remained practically unchanged, continuing to exhibit features typical for $\mathrm{Cu}^{2+}$ cations (Figure 2f), compensating charge of only the zeolite framework.

$\mathrm{UV}$-Vis spectra of aged bimetallic samples reduced at $25^{\circ} \mathrm{C}$ and $50{ }^{\circ} \mathrm{C}(\mathrm{Cu} 9 \mathrm{Ag} 1 \mathrm{CLI}-$

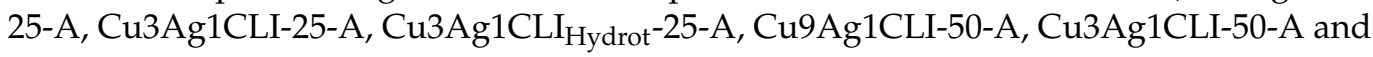


$\mathrm{Cu} 3 \mathrm{Ag} 1 \mathrm{CLI} \mathrm{Hydrot}^{-50-\mathrm{A}}$; see Figure 2e,f) also show bands characteristic of the $\mathrm{Cu}^{2+}$ ion. There is no evidence that the bands are associated to other copper species. Thus, it can be concluded that the reduced copper nanospecies, existing in fresh samples (Figure 2a,b) reduced at low temperatures of $25^{\circ} \mathrm{C}$ and $50{ }^{\circ} \mathrm{C}$ [26] were reoxidized to $\mathrm{Cu}^{2+}$ during storage. Indeed, the 800-850 $\mathrm{nm}$ band for the aforementioned aged bimetallic samples, reduced at $50{ }^{\circ} \mathrm{C}$ (Figure 2f), is somewhat more intense than the corresponding fresh samples (Figure 2b). At the same time, the structureless absorption base typical for metal blacks also decreased (see the difference in Figure $2 \mathrm{~b}, \mathrm{f}$ ). A weak feature at $560 \mathrm{~nm}$, characteristic of the copper plasma resonance band, which is noticeable in fresh bimetallic samples reduced at $50{ }^{\circ} \mathrm{C}$ (Figure $2 \mathrm{~b}$ ), completely disappears after storage (Figure $2 \mathrm{f}$ ).

Features at 270, 305, 320 and $380 \mathrm{~nm}$, typical of silver species, are observed in the spectra of bimetallic samples reduced at $25^{\circ} \mathrm{C}$ and $50{ }^{\circ} \mathrm{C}$, which become even more pronounced after aging (Figure 2e,f). The spectra of the Cu9Ag1CLI-50-F, Cu3Ag1CLI$50-\mathrm{F}$, and $\mathrm{Cu} 3 \mathrm{Ag} 1 \mathrm{CLI}_{\mathrm{Hydrot}}-50-\mathrm{F}$ samples (Figure $2 \mathrm{~b}$ ) show the presence of bands and/or shoulders centered at 320 and $380 \mathrm{~nm}$, which were associated with reduced species of silver. In previous studies [26,47], the band at $380 \mathrm{~nm}$ was associated to quasicolloidal silver species, while the bands at $270 \mathrm{~nm}, 305 \mathrm{~nm}$ and $320 \mathrm{~nm}$ belonged to $\mathrm{Ag}_{4}, \mathrm{Ag}_{2}{ }^{+}$and $\mathrm{Ag}_{8}$ clusters, respectively. A comparison between the spectra of fresh and aged samples allows to outline that some transformation of quasicolloidal silver to $\mathrm{Ag}_{8}$ clusters take place.

$\mathrm{Ag}_{2}{ }^{+}$and $\mathrm{Ag}_{4}$ clusters can be formed inside clinoptilolite channels. Taking into account that the maximum diameter of a sphere that can be included inside the cavities of clinoptilolite is $5.97 \AA$ [48], this is the upper limit for the size of the guest particles. This means that $\mathrm{Ag}_{8}$ clusters and quasicolloidal silver particles, the sizes of which are larger than the diameter of the clinoptilolite channels [49], can be located only on the outer surface of clinoptilolite crystals, or in the mesoporosity existing due to defects in the ideal crystal structure of clinoptilolite, in the interstitial spaces of particles constituting this mineral [50]. Finally, some of these silver species can be formed inside the mordenite channels (another zeolitic phase, represented in the minority in this natural material [26]); the maximum diameter of a sphere that can be included in the mordenite voids is $6.7 \AA$ [48]. These possibilities have been analyzed in previous studies [26,47] using the same natural clinoptilolite from the Tasajeras deposit. It is important to note that $\mathrm{Ag}^{+}$ions do not exhibit absorption in the studied UV-Vis range, which makes it complicated to discern their presence; however, the presence of $\mathrm{Ag}^{+}$cations in the samples should not be ruled out.

The peak at $400 \mathrm{~nm}$ in fresh bimetallic samples reduced at $50{ }^{\circ} \mathrm{C}(\mathrm{Cu}(\mathrm{x}) \mathrm{Ag}(\mathrm{y}) \mathrm{CLI}-50-\mathrm{F}$, Figure $2 \mathrm{~b}$ ) can be the result of overlapping of the $380 \mathrm{~nm}$ band and a broad silver plasma resonance peak at $410 \mathrm{~nm}$ that begin to be degraded and in the corresponding aged samples $(\mathrm{Cu}(\mathrm{x}) \mathrm{Ag}(\mathrm{y}) \mathrm{CLI}-50-\mathrm{A})$ exist as a shoulder of lower intensity (Figure 2f).

In the UV-Vis spectrum of aged monometallic sample CuCLI-150-A, reduced before aging at $150{ }^{\circ} \mathrm{C}$ (see Figure $2 \mathrm{~g}$ ) the presence of $\mathrm{Cu}^{2+}$ characteristic bands is also observed. In comparison, the intensity of the $\mathrm{Cu}^{2+} d-d$ transition band in the spectrum of a fresh CuCLI-150-F sample is lower than that of an aged CuCLI-50-A sample. This effect means that some part of copper is still in a reduced state. Besides this, the $550-560 \mathrm{~nm}$ band corresponding to colloidal copper particles of a nanometer size associated with surface plasmon resonance, which was observed in the spectrum of the CuCLI-150-F sample (see Figure 2c) disappears in the spectrum of CuCLI-150-A sample, confirming the oxidation of copper nanoparticles to $\mathrm{Cu}^{2+}$ cations that leads to an increase in the $d-d$ band intensity. In the spectrum of CuCLI-150-A, only the $475 \mathrm{~nm}$ band is observed, which belongs to unidentified species of reduced copper (see Figure $2 \mathrm{~g}$ ). This suggests that, in line with the oxidation of copper nanoparticles, the formation of another type of copper species could take place. Available studies about copper species that possess absorption spectra in the short-wavelength region are quite controversial, but the observed appearance of absorption in this range may be due to the formation of a few-atomic copper cluster $\left(\mathrm{Cu}_{n}\right)[51,52]$. 


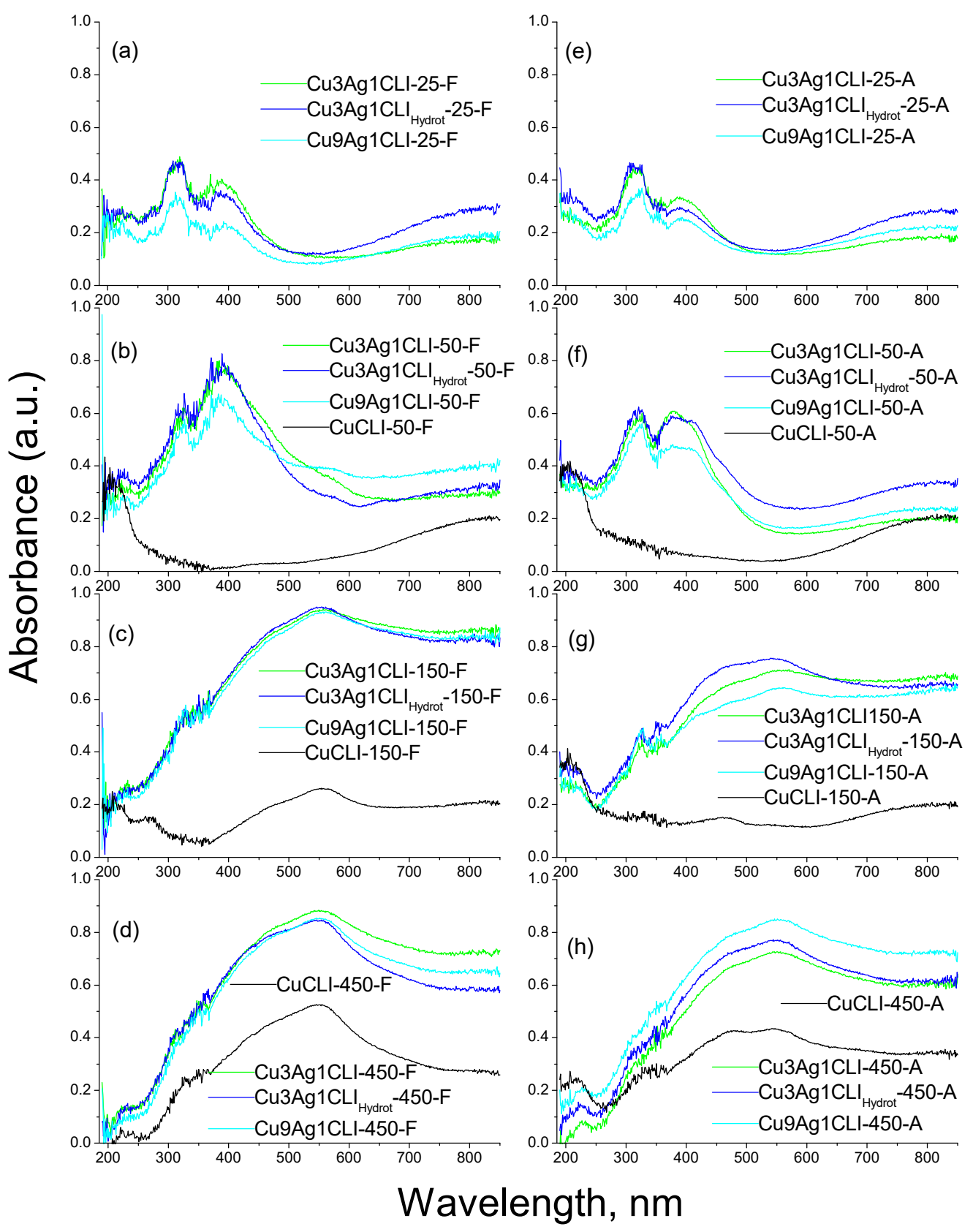

Figure 2. Subtractive spectra of the samples reduced at different temperatures, showing differences in optical density between the fresh $(\mathbf{a}-\mathbf{d})$ and aged $(\mathbf{e}-\mathbf{h})$ samples.

Thus, the CuCLI-150-A sample contains mainly $\mathrm{Cu}^{2+}$ cations and a few-atomic copper cluster. Both types of copper species appear as a result of the decomposition and oxidation of copper particles. The poor stability of copper nanoparticles supported on various porous matrices has also been discussed by other authors [22,24,31], reporting the rapid disappearance of the plasma resonance feature associated with copper nanoparticles.

On the contrary, the UV-Vis spectra corresponding to all bimetallic samples reduced at $150{ }^{\circ} \mathrm{C}$ (see Figure $2 \mathrm{c}, \mathrm{g}$ ) do show very different behavior. In the spectra of fresh samples (Figure 2c) the band at 550-560 $\mathrm{nm}$ is clearly visible. The spectra of aged samples (Figure 2g) show that this band at 550-560 $\mathrm{nm}$ is slightly less intense, while the $d-d$ band of copper ions is still not observed (Figure 2c,g), and the only sign of the presence of $\mathrm{Cu}^{2+}$ is the appearance of a weak, but undoubtedly observable band at $207 \mathrm{~nm}$.

Slight changes in the shape of the plasma resonance feature and the appearance of a shoulder at $420-440 \mathrm{~nm}$ can be associated with a slight decrease in the average size of copper 
particles due to oxidation that occurs during storage. It was previously reported [53] that the size of particles affects the shape of this absorption feature, evolving from a shoulder in the case of a smaller size to a pronounced peak for larger particles. Hence, the presence of silver affects the oxidation mechanism and the stability of the reduced copper particles. This could be an important alternative way to reduce reoxidation of reduced copper species.

Sample CuCLI-450-A (Figure $2 \mathrm{~h}$ ) is the only material from aged monometallic copper samples which shows in the UV-Vis spectrum aband at 550-560 nm due to plasma resonance; however, the intensity to this band is markedly reduced compared to the spectrum of a fresh CuCLI-450-F sample (Figure 2d). Besides this, a $475 \mathrm{~nm}$ band emerges in the spectra of CuCLI-450-A, see Figure 2h; this is the same as in the spectrum of the CuCLI-150-A sample (Figure $2 \mathrm{~g}$ ), which is presumably associated with copper clusters $\left(\mathrm{Cu}_{n}\right)$.

These results permit to discuss some general considerations about the mechanism of oxidation of copper particles supported on a zeolite. Upon reduction, first, copper cations $\mathrm{Cu}^{2+}$ are reduced to $\mathrm{Cu}^{+}$and/or to neutral atoms. Next, the products of reduction diffuse and agglomerate, forming, as a result, charged or neutral species of different sizes (nuclearity) depending on the conditions such as the temperature of reduction, the structure and composition of the zeolite matrix (type of counter-cation/cations, framework Si/Al ratio), and on the presence of other species. In our case, not only monometallic species of copper and silver can be formed; the formation of bimetallic $\mathrm{Cu}-\mathrm{Ag}$ particles is not excluded a priori. In the case of mordenite [31], a very different behavior was observed; up to a temperature of $400{ }^{\circ} \mathrm{C}, \mathrm{Ag}_{8}$ clusters were formed independently of copper particles, and there was no evidence of the formation of particles of mixed composition.

Thus, the data [31] confirm the selective stabilization of $\mathrm{Ag}_{8}$ clusters in the mordenite matrix, and the separate formation of $\mathrm{Cu}$ nanoparticles. In our case, smaller silver clusters are formed on the clinoptilolite matrix at low reduction temperatures, and at $150{ }^{\circ} \mathrm{C}$ they can be deduced only as minority species. It can be concluded that the interaction of the reduced particles with the matrix, taking into account the steric constraints imposed by the sizes of intrazeolithic voids, and the affinity of the species formed during agglomeration to the matrix really plays a decisive role in the distribution of the obtained reduced components in the final mixture of reduced and agglomerated products. The selective formation of $\mathrm{Ag}_{8}$ clusters in mordenite and their extraordinary stability against agglomeration in a wide temperature range and against oxidation during storage in air $[51,53,54]$ is a property that appears due to the interaction with the mordenite matrix. The matrix of another zeolite, erionite, demonstrates a smaller range of temperature stability of Ag 8 clusters [55], probably due to the smaller diameter of the channels, while the clinoptilolite matrix does not show this peak for the synthetic clinoptilolite sample, but shows a low-intensity peak of these clusters only for the natural sample, with an mixture of some impurity of the mordenite phase [47], which allows us to conclude that mordenite is responsible for the appearance of this specie. At the same time, silver species with an absorption maximum at $380 \mathrm{~nm}$ [47], which has never been observed for mordenite, are very easily formed in the clinoptilolite matrix. Thus, it can be concluded that the size and topology of the zeolite channels predetermine the type of reduced species, if any are formed, while the aggregates formed in the mesoporosity and on the outer surface of the zeolite crystals can have any size, limited only by the availability of the reduced material and coefficient of diffusion on the matrix surface.

Typically, cluster formation is a random process in which clusters of different sizes are formed. The cluster size is commonly understood as the number of atoms forming the cluster rather than its linear dimensions. Clusters can range in size from several to hundreds of atoms, and an ensemble of clusters is usually characterized by a fairly wide size distribution.

It is well known that there are so-called "magic numbers" for a sequence of growing clusters, which means that clusters with just this particular characteristic number of atoms are more stable compared to other clusters with a random size. Two reasons can explain the stability of such selected structures. First, if electronic effects predominate, just as the filled 
electron shell correlates with the stability and reactivity of an atom, the filled electronic shells in the jellium model with the corresponding number of electrons in magic clusters leads to exceptionally stable clusters [56]. Electronic magic numbers $(n=2,8,18,20,34$ and 40) due to the closure of the electronic shell and even-odd alternation due to electron pairing at the highest occupied molecular level were found in theoretical calculations for $\mathrm{Cu}$ clusters [57,58].

Second, if electronic effects are not dominant, magic numbers are often a count of the numbers of spheres in a tightly packed compact structures, such as icosahedral magically stable gold clusters formed by 13,55, 147, 309, and 561 atoms, which corresponds to the five smallest possible closed shell structures, and octahedral model clusters of palladium $\operatorname{Pd}_{\mathrm{n}}$ with $n=13,19,38,55,79$, and 147 atoms [59]. Higher symmetry clusters provide more contacts for the atoms that form them. Relatively stable copper clusters have higher symmetry and usually have a closed structure. For example, $\mathrm{Cu}_{13}$ and $\mathrm{Cu}_{55}$ have $\mathrm{I}_{\mathrm{h}}$ symmetry, while $\mathrm{Cu}_{26}$ and $\mathrm{Cu}_{38}$ exhibit $\mathrm{T}_{\mathrm{d}}$ and $\mathrm{O}_{\mathrm{h}}$ symmetry, respectively [60].

Under conditions of rapid growth, a wide range of cluster sizes appears. These reduced species then begin to slowly oxidize upon contact with the carrier and oxygen at ambient conditions. First of all, if agglomerations of copper atoms give rise to large nanoparticles, the size of which exceeds the cross-section of zeolite channels, and, accordingly, these particles are located on the outer surface of zeolite particles, one can expect the formation of a copper oxide shell followed by complete oxidation to $\mathrm{CuO}$ nanoparticles. Such samples of specially prepared copper oxide deposited on a mordenite matrix have a wide band in the optical spectra [61].

No evidence of the formation of $\mathrm{CuO}$ particles can be seen from the UV-Vis spectra; on the contrary, the spectra of aged samples show the features of $\mathrm{Cu}^{2+}$. This means that the oxidation of copper particles occurs due to the oxidation of copper atoms from their surface and the diffusion of the formed $\mathrm{Cu}^{2+}$ ions to exchange sites inside the zeolite matrix and returns to their original role of exchangeable cations in the zeolite framework. Such a process means that even on the surface of clinoptilolite, copper particles are strongly influenced by the zeolite, while after the reduction of copper cations in a hydrogen flow, protons remain as compensating ions. This means that the acid sites of the zeolite play an important role in the oxidation of copper particles.

Another expected effect is that the more stable species will oxidize more slowly, gradually changing distribution in the reduced mixture, so that finally only the most stable species will survive.

Finally, while a metal particle is oxidized by this "atom-by-atom" mechanism, changing its size from $\mathrm{N}$ to $(\mathrm{N}-1),(\mathrm{N}-2)$ and so on, as soon as it begins to have a magic size its oxidation will slow down. All these effects will lead to a modification of the optical spectra of the initial mixture and the manifestation of the spectral features of the most stable magic clusters and nanoparticles, which is well pronounced in the observed spectra, for example, the band at $475 \mathrm{~nm}$, Figure 2g,h. Therefore, the decomposition of copper particles formed in the monometallic CuCLI-150-F and CuCLI-450-F samples occurs by a mechanism that may include the development of a few-atomic cluster as an intermediate stage before complete oxidation to $\mathrm{Cu}^{2+}$ cations.

The UV-Vis spectra of all $\mathrm{Cu}(\mathrm{x}) \mathrm{Ag}(\mathrm{y}) \mathrm{CLI}-450-\mathrm{A}$ samples (Figure $2 \mathrm{~h}$ ) give evidence of the presence of metal particles, demonstrating the corresponding bands of surface plasmon resonance. They may belong to copper particles, but the formation of mixed $\mathrm{Cu}(\mathrm{x}) \mathrm{Ag}(\mathrm{y})$ particles cannot be completely excluded. The synthesis of $\mathrm{Ag}-\mathrm{Cu}$ alloy nanoparticles was revised in [44], showing spectra with a gradual displacement between the position typical for silver and for copper plasmons (see Figure 14 in Ref. [44], and Ref. [62]). An interesting point is the magic numbers for nanoparticles of $\mathrm{Cu}$-Ag alloys [63], and the influence of supports on the observed magic numbers [64].

The general observation is that the results agree with those obtained and reported in [26] for all $\mathrm{Cu}(\mathrm{x}) \mathrm{Ag}(\mathrm{y}) \mathrm{CLI}-450-\mathrm{F}$ samples, which demonstrates the increased stability of reduced metal particles in binary systems as compared with monometallic systems. 


\subsection{X-ray Diffraction}

To obtain more information on the presence and stability of copper and silver particles in reduced and subsequently aged bimetallic samples, an X-ray diffraction (XRD) study was performed (Figure 3).

XRD patterns of all bimetallic $\mathrm{Cu}(\mathrm{x}) \mathrm{Ag}(\mathrm{y}) \mathrm{CLI}-450-\mathrm{A}$ samples reduced at $450{ }^{\circ} \mathrm{C}$, even after long-term storage, show peaks at $43.2^{\circ}$ and $50.3^{\circ}$, corresponding to metal copper, and peaks at $38.11^{\circ}$ and $44.29^{\circ}$ corresponding to metal silver. These results are consistent with the aforesaid on UV-Vis spectra and confirm the presence of metallic copper and silver particles, which raises doubts about the presence of alloy particles. Those may be too small to show a diffraction pattern, or they can be present in small quantities. These diffraction peaks of $\mathrm{Cu}$ and $\mathrm{Ag}$ were present in all fresh $\mathrm{Cu}(\mathrm{x}) \mathrm{Ag}(\mathrm{y}) \mathrm{CLI}-450-\mathrm{F}$ samples [26]. The decline in their intensities in aged samples takes place, but the peak of silver at $38.11^{\circ}$ continues to be the most intense, see Figure 3. The ratios of the intensities of the Ag and $\mathrm{Cu}$ peaks to the intensity of the quartz $(\mathrm{Q})$ peak $\left(26.25^{\circ}\right), \mathrm{I}_{\mathrm{S}} / \mathrm{I}_{\mathrm{Q}}$, for both fresh and aged samples (S) are collected in Table 1. Quartz as a natural impurity is present in all samples and does not undergo any changes in the applied treatments, therefore it is used as an internal standard. The quartz content is constant for all studied samples. The observed decrease in the intensities of the $\mathrm{Cu}$ and $\mathrm{Ag}$ peaks is consistent with the observations made earlier in the analysis of the UV-Vis spectra. These results confirm the increased stability of these reduced metallic copper and silver particles in the binary $\mathrm{Cu}(\mathrm{x}) \mathrm{Ag}(\mathrm{y}) \mathrm{CLI}-450$ system.

XRD patterns of aged bimetallic $\mathrm{Cu}(\mathrm{x}) \mathrm{Ag}(\mathrm{y}) \mathrm{CLI}-150-\mathrm{A}$ samples, reduced at $150{ }^{\circ} \mathrm{C}$, also show peaks at $38.11^{\circ}$ and $44.29^{\circ}$, corresponding to metal silver. These peaks have a lower intensity compared to fresh bimetallic $\mathrm{Cu}(\mathrm{x}) \mathrm{Ag}(\mathrm{y}) \mathrm{CLI}-150-\mathrm{F}$ samples [26] (Table 1). Thus, some amount of silver particles formed in the reduced fresh samples was oxidized to $\mathrm{Ag}(\mathrm{I})$ species and/or converts into silver particles of smaller size and silver clusters, in this way becoming "invisible" to XRD. This is consistent with the UV-Vis data, which make evident the formation of $\mathrm{Ag}_{8}$ clusters as a result of the decomposition of silver particles.

Note (Table 1) that for both metals, the ratio of the relative intensity differs between the two peaks for different crystallographic planes with distinct $h k l$ (represented in Table 1 by 20). This effect confirms the complex nature of the stepwise sequence of oxidation of metal particles, while a variation of the relative intensity of diffraction peaks is most likely associated with a change in the shape of metal particles during oxidation and dissolution, and then with the observed evolution of various facets of particles, which occurs in a different way. However, this issue goes beyond the scope of our study and should be studied and published elsewhere.

For aged bimetallic $\mathrm{Cu}(\mathrm{x}) \mathrm{Ag}(\mathrm{y}) \mathrm{CLI}-150-\mathrm{A}$ samples reduced a $150{ }^{\circ} \mathrm{C}$, no copper metal peak is observed. The presence of a plasmon peak of copper nanoparticles, shown by UVVis spectroscopy, and the absence of the peaks of bulk copper in the XRD patterns of both fresh and aged samples make evident that under this temperature reduced copper does not agglomerate in particles larger than a few nanometers, that is, does not form a "copper black", which is consistent with what was obtained and reported [26] for $\mathrm{Cu}(\mathrm{x}) \mathrm{Ag}(\mathrm{y}) \mathrm{CLI}-$ 150-F samples. 

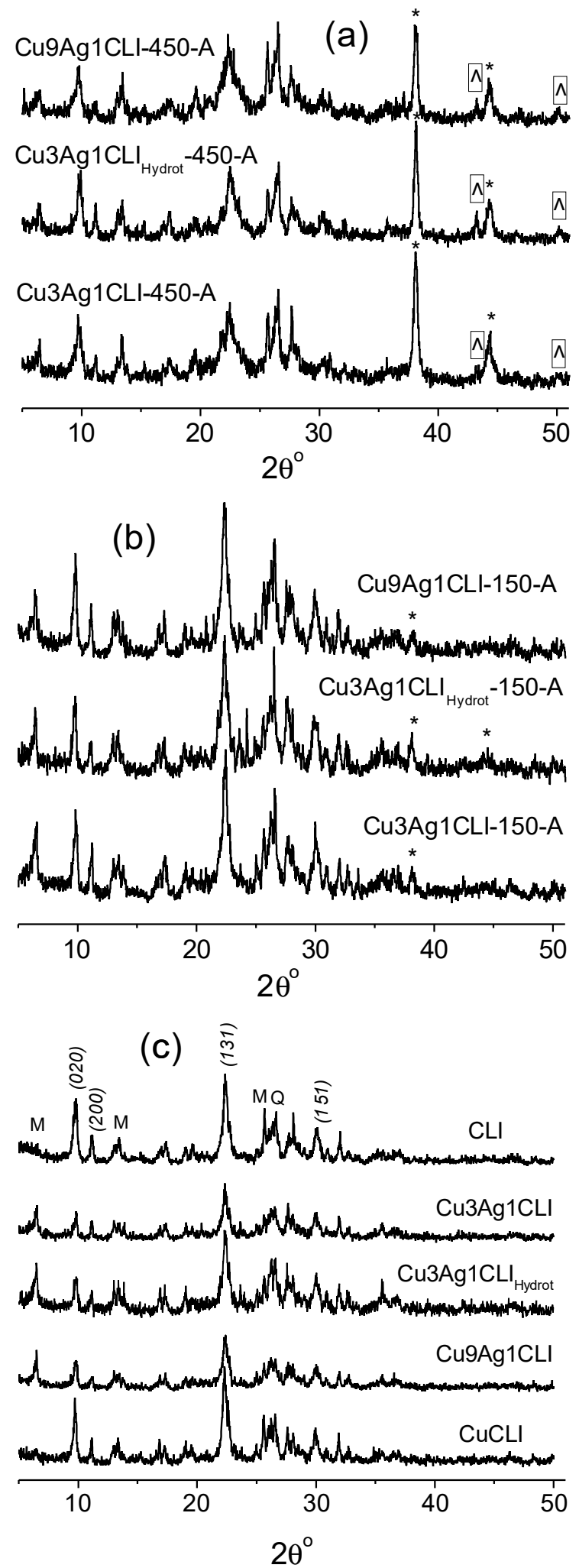

Figure 3. XRD patterns of the aged bimetallic samples reduced at $150{ }^{\circ} \mathrm{C}(\mathbf{b})$ and $450{ }^{\circ} \mathrm{C}(\mathbf{a})$. The peaks belonging to metallic silver and copper are marked with "*" and "^" symbols respectively. Patterns of the starting natural clinoptilolite and exchanged but not yet reduced samples are included (c). The Miller indexes $(h k l)$ of the main diffraction peaks for clinoptilolite are shown. The main diffraction peaks of mordenite $(\mathrm{M})$ and quartz $(\mathrm{Q})$ are shown also. 
Table 1. Intensity ratio $\mathrm{I}_{\mathrm{S}} / \mathrm{I}_{\mathrm{Q}}$ of the main diffraction peaks of $\mathrm{Ag}$ and $\mathrm{Cu}$ relatively to quartz peak at $2 \theta=26.25^{\circ}$.

\begin{tabular}{|c|c|c|c|c|c|}
\hline Metal & Ag & & $\mathrm{Cu}$ & \multirow{2}{*}{\multicolumn{2}{|c|}{$50.3^{\circ}$}} \\
\hline $2 \theta,\left[^{\circ}\right]$ & $38.12^{\circ}$ & $44.29^{\circ}$ & $43.2^{\circ}$ & & \\
\hline Samples & \multicolumn{2}{|c|}{$\mathbf{I}_{\mathbf{S}} / \mathbf{I}_{\mathbf{Q}}$} & \multicolumn{3}{|c|}{$\mathbf{I}_{\mathbf{S}} / \mathbf{I}_{\mathbf{Q}}$} \\
\hline Cu3Ag1CLI ${ }_{\text {Hydrot }}-150-F$ & 1.360 & 0.573 & & 0 & 0 \\
\hline Cu3Ag1CLI Hydrot $^{-150-A}$ & 0.608 & 0.400 & & 0 & 0 \\
\hline (Ratio Aged/Fresh) & $(0.45)$ & $(0.70)$ & & (0) & (0) \\
\hline Cu3Ag1CLI-150-F & 1.270 & 0.395 & & 0 & 0 \\
\hline Cu3Ag1CLI-150-A & 0.486 & 0.222 & & 0 & 0 \\
\hline (Ratio Aged/Fresh) & $(0.38)$ & $(0.56)$ & & (0) & (0) \\
\hline Cu9Ag1CLI-150-F & 1.017 & 0.625 & & 0 & 0 \\
\hline Cu9Ag1CLI-150-A & 0.384 & 0.246 & & 0 & 0 \\
\hline (Ratio Aged/Fresh) & $(0.38)$ & $(0.39)$ & & $(0)$ & (0) \\
\hline Cu3Ag1CLI $\mathrm{Hydrot}^{-450-F}$ & 3.476 & 1.428 & & 0.857 & 0.542 \\
\hline Cu3Ag1CLI Hydrot $^{-450-A}$ & 2.680 & 1.085 & & 0.744 & 0.382 \\
\hline (Ratio Aged/Fresh) & $(0.77)$ & $(0.76)$ & & $(0.87)$ & 0.70 \\
\hline Cu3Ag1CLI-450-F & 3.460 & 1.180 & & 0.540 & 0.400 \\
\hline Cu3Ag1CLI-450-A & 1.666 & 0.637 & & 0.289 & 0.246 \\
\hline (Ratio Aged/Fresh) & $(0.48)$ & $(0.54)$ & & (0.53) & 0.61 \\
\hline Cu9Ag1CLI-450-F & 2.519 & 0.923 & & 0.857 & 0.452 \\
\hline Cu9Ag1CLI-450-A & 1.416 & 0.633 & & 0.744 & 0.382 \\
\hline (Ratio Aged/Fresh) & $(0.56)$ & $(0.68)$ & & $(0.87)$ & $(0.84)$ \\
\hline
\end{tabular}

The ratio of $\mathrm{I}_{\mathrm{S}} / \mathrm{I}_{\mathrm{Q}}$ values of aged samples and fresh samples (Ratio Aged/Fresh) is given in parenthesis.

XRD patterns of aged bimetallic samples reduced at the lowest temperatures of $25^{\circ} \mathrm{C}$ and $50{ }^{\circ} \mathrm{C}$ (not shown) do not display evidence of agglomerated copper species, which are also not visible in the UV-Vis spectra. Only quasicolloidal silver particles $(\sim 1 \mathrm{~nm})$ and clusters are observed in the optical spectra, and they are surprisingly stable. In our previous studies [47], with this same natural clinoptilolite and synthetic one, monometallic $\mathrm{Ag}^{+}$only samples exchanges and then thermally reduced in hydrogen, the obtained diffraction patterns of the samples reduced at $100{ }^{\circ} \mathrm{C}$ didn't show the presence of metallic silver. The UV-Vis spectra of these same samples reduced at $100^{\circ} \mathrm{C}$ also did not show surface plasmon resonance of silver nanoparticles; only quasicolloidal particles $(\sim 1 \mathrm{~nm})$ and clusters of this metal were evidenced. It is important to note that, similarly to this reduced monometallic silver natural-clinoptilolite system [47], in the reduced bimetallic $\mathrm{Cu}-\mathrm{Ag}$ systems, which are the subject of the present study, the formation of $\mathrm{Ag}_{8}$ clusters was also observed. In contrast, the reduced monometallic silver system supported on synthetic clinoptilolite [47] showed no evidence of the formation of this type of clusters. Thus, it can be outlined that the natural clinoptilolite matrix (containing mordenite zeolite as an impurity phase) plays an important role in the stabilization of $\mathrm{Ag}_{8}$ clusters. This is consistent with the aforesaid for bimetallic $\mathrm{Cu}-\mathrm{Ag}$ systems reduced at a lower temperature, where UV-Vis spectra showed that some of the quasicolloidal silver presented in fresh samples after aging is transformed into $\mathrm{Ag}_{8}$ clusters.

\subsection{Scanning Electron Microscopy (SEM)}

In order to get even more detailed information about the metal particles preserved on the aged bimetallic samples, SEM images of the initial sample, in which the ion exchange was carried out at $100^{\circ} \mathrm{C}\left(\mathrm{Cu} 3 \mathrm{Ag} 1 \mathrm{CLI} \mathrm{Hydrot}_{\text {; }}\right.$ see Table 2$)$ and the sample prepared from it, while reduced at the highest temperature $\left(\mathrm{Cu} 3 \mathrm{Ag} 1 \mathrm{CLI}_{\mathrm{Hydrot}}-450-\mathrm{A}\right)$ and after long-term storage, were obtained. Figures $4 \mathrm{a}$ and $5 \mathrm{a}$ display these images, demonstrating the presence of silver particles on both aged samples; the EDS spectra of both samples are shown in Figures $4 \mathrm{~b}$ and $5 \mathrm{~b}$. It can be observed that the particles are uniformly distributed on 
the zeolite surface of both samples. From these figures, it can be inferred that particles are larger in the $\mathrm{Cu} 3 \mathrm{Ag} 1 \mathrm{CLI} \mathrm{Hydrot}-450-\mathrm{A}$ compared with the aged, exchanged sample $\left(\mathrm{Cu} 3 \mathrm{Ag} 1 \mathrm{CLI} \mathrm{Hydrot}^{-} \mathrm{A}\right)$. Most of the particles on $\mathrm{Cu} 3 \mathrm{Ag} 1 \mathrm{CLI}_{\mathrm{Hydrot}}-\mathrm{A}$ have a size of about $100 \mathrm{~nm}$ or below this value, nevertheless, other aggregated particles with a larger size are observed (see the particle indicated by the black arrow in Figure 5a). Several particles with a size of about $100 \mathrm{~nm}$ are observed on $\mathrm{Cu} 3 \mathrm{Ag} 1 \mathrm{CLI}_{\mathrm{Hydrot}}-450-\mathrm{A}$. However, in this latter sample, there is a greater number of aggregate particles with a size exceeding this value $(100 \mathrm{~nm})$ compared to its aged, exchanged counterpart (without reduction). The difference in the sizes of particles between the two samples can be explained by differences in the process of their formation. In an aged ion-exchange sample, the formation of silver particles occurs as a result of $\mathrm{Ag}^{+}$cation degradation during storage, which leads to a reduced silver species. This is consistent with the low stability of $\mathrm{Ag}^{+}$cation and the well-known photoreduction processes that can occur in it [65]. In the case of Cu3Ag1CLI $\mathrm{Hydrot}^{-450-}$ $\mathrm{A}$, particles are produced by the process of $\mathrm{Ag}^{+}$thermal reduction with hydrogen. This latter reduction process is more extensive, producing more aggregated, larger species. $\mathrm{Ag}^{+}$ degradation during storage of the exchanged sample is a slower process that takes place more slowly, relative to the thermal reduction one. For both processes, the first step of reduction involves the formation of $\mathrm{Ag}^{\mathrm{O}}$ atoms, which are gradually agglomerated, forming dimers, trimers, etc. and clusters of different sizes. Then, they aggregate to form larger particles. This aggregation process continues until a stable size is obtained.

Table 2. Copper and silver contents and temperature of exchange for the samples used in this work.

\begin{tabular}{lllll}
\hline Samples & $\mathrm{CuCLI}$ & $\mathrm{Cu} 3 \mathrm{Ag1CLI}$ Hydrot & Cu3Ag1CLI & Cu9Ag1CLI \\
\hline $\mathrm{Cu}(\mathrm{wt} \%)$ & 3.40 & 3.16 & 1.44 & 1.50 \\
\hline $\mathrm{Ag}(\mathrm{wt} \%)$ & - & 3.71 & 3.80 & 2.23 \\
\hline Temperature & $100{ }^{\circ} \mathrm{C}$ & $100{ }^{\circ} \mathrm{C}$ & room & room \\
\hline Solution & $\mathrm{Cu}\left(\mathrm{NO}_{3}\right)_{2}$ & $\mathrm{Cu}\left(\mathrm{NO}_{3}\right)_{2}-\mathrm{AgNO}_{3}$ & $\mathrm{Cu}\left(\mathrm{NO}_{3}\right)_{2}-\mathrm{AgNO}_{3}$ & $\mathrm{Cu}\left(\mathrm{NO}_{3}\right)_{2}-\mathrm{AgNO}_{3}$ \\
\hline
\end{tabular}

Numbers in the designations of bimetallic samples indicates the $\mathrm{Cu}\left(\mathrm{NO}_{3}\right)_{2} / \mathrm{AgNO}_{3}$ volume ratio used during ion exchange.

The same is evidenced by a more meticulous observation of the UV-Vis spectra shown in Figure 1b, which show a correlation with the observed SEM data. Thus, a broad absorption peak centered at $385 \mathrm{~nm}$ can be observed in the spectra of exchanged bimetallic samples (Figure 1b). This adsorption is typical for reduced silver, which corresponds to the silver particles observed on SEM images. Besides this, it was observed that the features at 270, 305, 320 and $380 \mathrm{~nm}$, typical for reduced silver nanospecies, observed in the spectra of bimetallic samples reduced at $25^{\circ} \mathrm{C}$ and $50{ }^{\circ} \mathrm{C}$, become even more defined after aging (Figure 2e,f).

It is important to outline that the degradation of the $\mathrm{Ag}^{+}$cation to form $\mathrm{Ag}^{\mathrm{O}}$ is not a common phenomenon observed for zeolites exchanged with this metallic cation. In general, when studying the formation of silver particles, several routes for its preparation were considered [65]. Photochemical reduction of silver ions under the action of light is based on the electron-transfer from a solvent molecule (for example, $\mathrm{H}_{2} \mathrm{O}$ ) to the electronically excited state of $\mathrm{Ag}^{+}$with the formation of $\mathrm{Ag}^{\mathrm{O}}$. During this process, $\mathrm{H}^{+}$(a simplified representation of $\mathrm{H}_{3} \mathrm{O}^{+}$) and $\mathrm{OH}^{\bullet}$ radical are formed from water in aqueous solutions. In this sense, it can be assumed that, during prolonged aging of the ion-exchange sample $\left(\mathrm{Cu} 3 \mathrm{Ag} 1 \mathrm{CLI}_{\mathrm{Hydrot}}\right)$, the $\mathrm{Ag}^{+}$ions, originally located as compensation cations in the clinoptilolite extra-framework sites, are reduced and replaced by $\mathrm{H}^{+}$formed from a water molecule in the zeolite. 


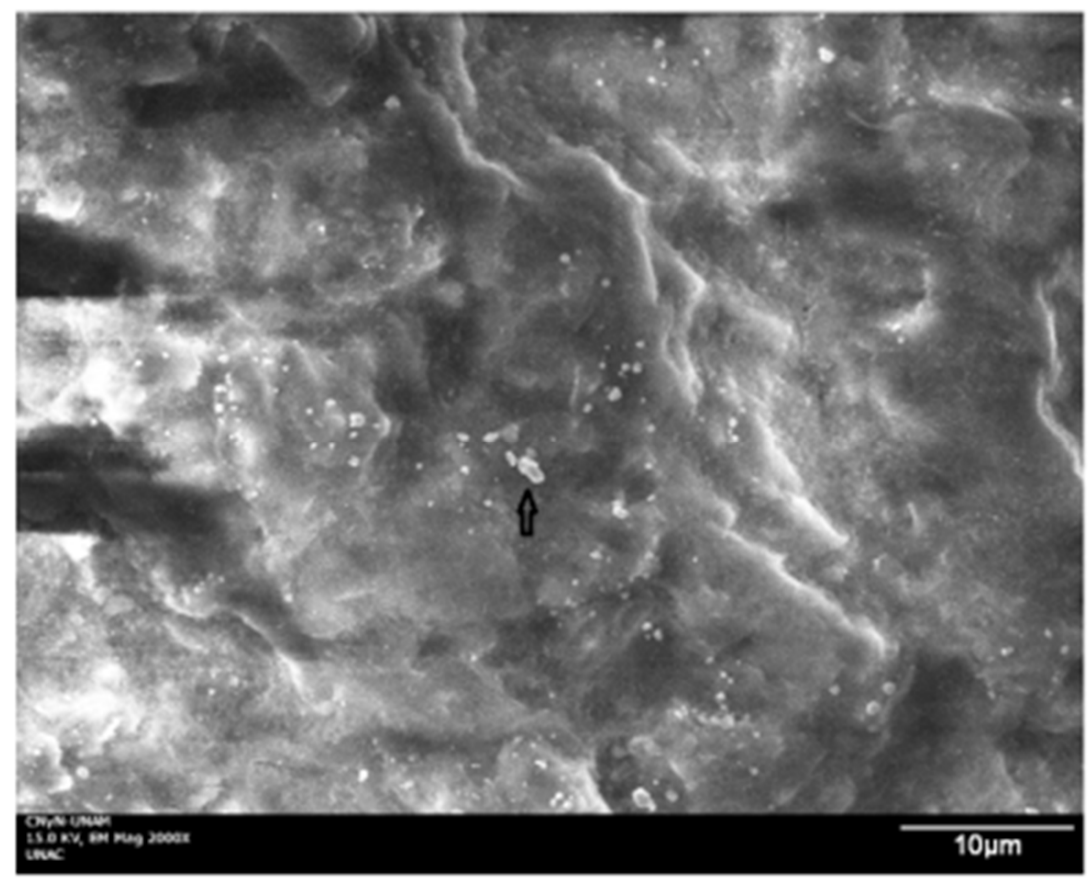

(a)

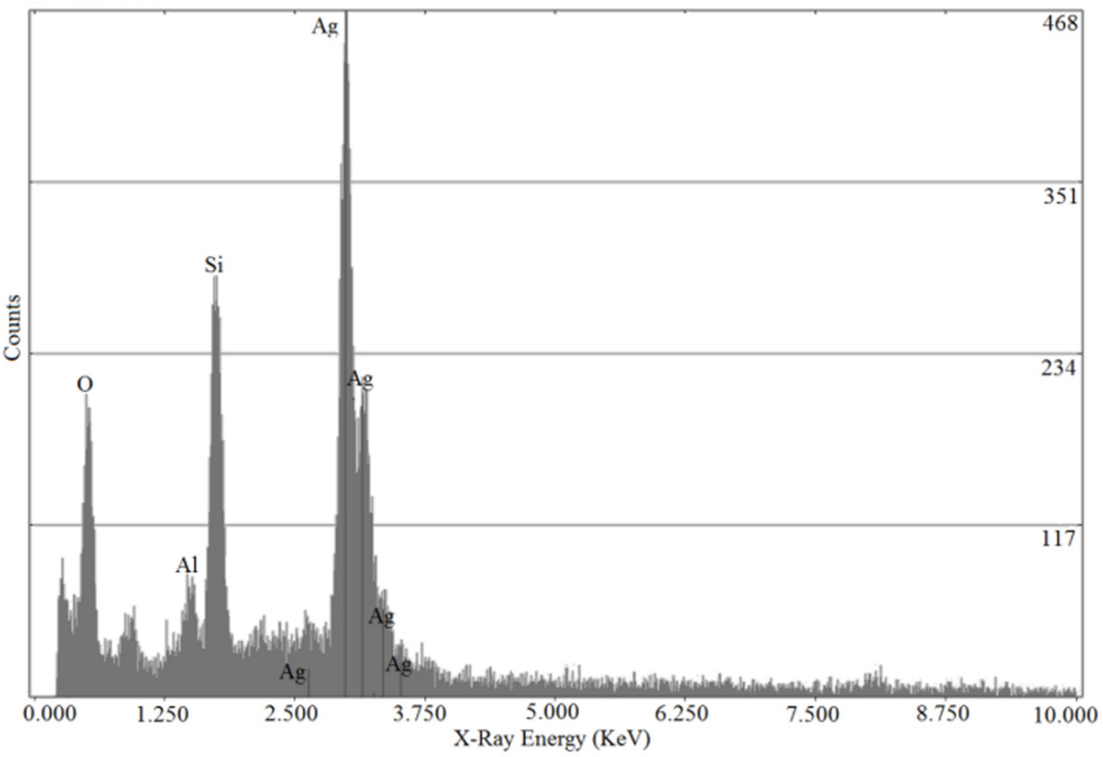

(b)

Figure 4. SEM image (a) of the aged bimetallic sample reduced at $450{ }^{\circ} \mathrm{C}(\mathrm{Cu} 3 \mathrm{Ag} 1 \mathrm{CLI} \mathrm{Hydrot}-450-\mathrm{A})$ showing the presence of silver particles on sample surface. EDS spectrum (b) of a silver particle (indicated with black arrow in (a)) is shown too. 


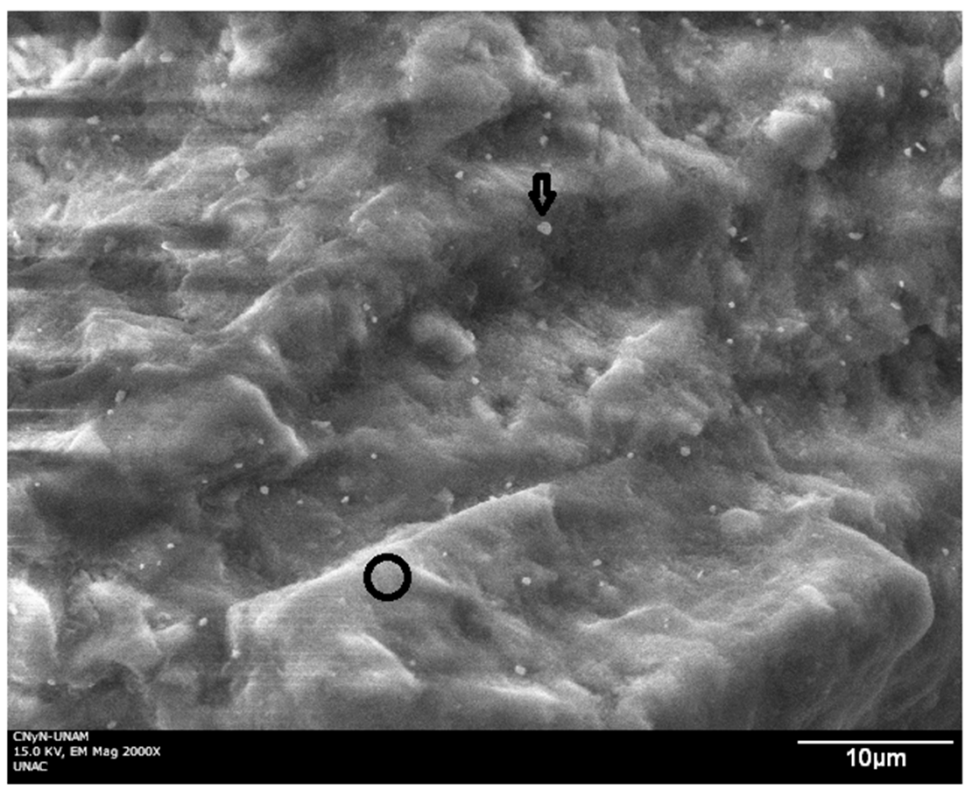

(a)

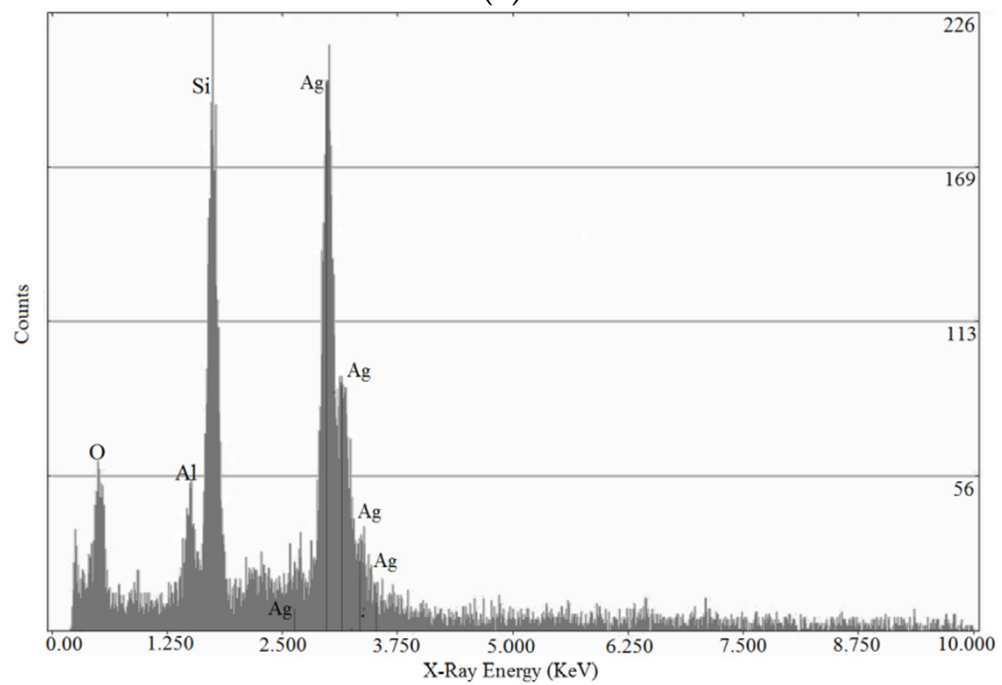

(b)

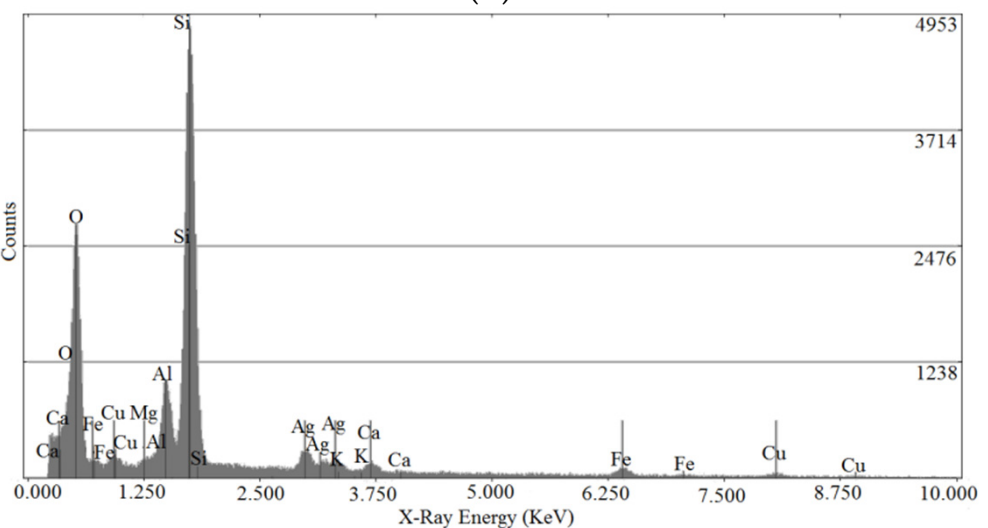

(c)

Figure 5. SEM image (a) of the aged $\mathrm{Cu} 3 \mathrm{Ag} 1 \mathrm{CLI} \mathrm{H}_{\mathrm{H} d r o t}$ sample, showing the presence of silver particles on sample surface. EDS spectra obtained on a silver particle (indicated with black arrow in (a)) and on zeolite matrix zone (indicate with black circle in (a)) are shown in (b) and (c) respectively. 


\section{Materials and Methods}

Purified samples of natural clinoptilolite were obtained from zeolitic rock of the Tasajeras deposit (Cuba). In accordance with the procedure presented in Ref. [26], they were exchanged with $0.1 \mathrm{M}$ monometallic $\mathrm{Cu}^{2+}$ and mixed bimetallic $\mathrm{Cu}^{2+}-\mathrm{Ag}^{+}$solutions with different $\mathrm{Cu} / \mathrm{Ag}$ ratios. The exchange treatment was carried out at room temperature for mixed solutions with a $\mathrm{Cu} / \mathrm{Ag}$ ratio of $3 / 1$ and $9 / 1$, and at a temperature of $100{ }^{\circ} \mathrm{C}$ for monometallic and mixed solutions with $\mathrm{Cu} / \mathrm{Ag}$ ratio of $3 / 1$. This last sample is referred to as "Hydrot" through the text and figures. Then, the exchanged samples were reduced for $4 \mathrm{~h}$ in a hydrogen flow at one of the selected temperatures: $25^{\circ} \mathrm{C}, 50^{\circ} \mathrm{C}, 150{ }^{\circ} \mathrm{C}$ and $450{ }^{\circ} \mathrm{C}$. Some details of sample preparation and the metal content, determined by the EDS for freshly prepared samples are listed in Table 2. Samples were marked as metal symbols with indices denoting ratios of metals in the ion-exchange solution and the type of zeolite, CLI (clinoptilolite), followed by the temperature of reduction in ${ }^{\circ} \mathrm{C}$, if applied; for example, Cu9Ag1CLI-450, or Cu3Ag1CLI $\mathrm{Hydrot}^{-450 .}$

The materials obtained immediately after the exchange and the reduction were investigated and the results were reported in [26]. The samples were then stored under ambient conditions for 30 months. The storage conditions can be resumed as: samples into closed containers, temperature changes between 18 and $30^{\circ} \mathrm{C}$, without permanent exposure to light or ambient humidity ( $80 \%$ average).

After this period, X-ray diffraction (XRD) patterns, UV-Vis diffuse reflectance spectra and scanning electron microscopy (SEM) images of these stored samples were again obtained. XRD patterns were recorded on a Philips X'Pert diffractometer (Almelo, Netherlands) equipped with a curved graphite monochromator, using $\mathrm{CuK}_{\alpha}(\lambda=0.154 \mathrm{~nm})$ radiation. UV-Vis spectra were taken with a Varian Cary 300 spectrometer (California, USA) equipped with a standard diffuse reflectance unit using barium sulfate as a reference. SEM images were obtained in a JEOL JSM-5300 scanning electron microscope (Tokyo, Japan) equipped with a Kevex Super Dry EDS (energy disperse spectroscopy) apparatus. Elemental quantification was done using the standard Magic 5 software. Through the text and figures samples will be marked in a similar manner, adding the designations $\mathrm{F}$ (fresh) and $\mathrm{A}$ (aged) for fresh and stored long time samples, respectively, for example, Cu9Ag1CLI-450-A sample.

\section{Conclusions}

A comprehensive study of long-term changes and stability of copper-silver species, obtained by the exchange of $\mathrm{Cu}^{2+}$ and $\mathrm{Ag}^{+}$on natural clinoptilolite, and then reduced in a hydrogen flow at different temperatures, was carried out.

It turned out that even after 30 months of storage under ambient conditions, studies by UV-Vis diffuse reflectance spectroscopy and X-ray diffraction reliably confirm the presence of reduced copper and silver nanospecies, including clusters and nanoparticles, in the samples under study. For bimetallic systems, a significantly higher stability is observed in comparison with monometallic $\mathrm{Cu}$-clinoptilolite, reduced under equal conditions. SEM images and EDS spectra obtained from aged bimetallic samples reduced at the highest temperature $\left(450{ }^{\circ} \mathrm{C}\right)$ and aged initial ion-exchange prototypes showed the presence of silver particles in both samples, assuming that during storage of the initial ion-exchanged bimetallic sample (without reduction) degradation of $\mathrm{Ag}^{+}$cations occurs. The process consists in the formation of silver particles with a predominant size of about $100 \mathrm{~nm}$. Particles are evenly distributed on the zeolite surface of both aged samples, being larger in the reduced bimetallic sample compared to its initial ion-exchanged prototype.

The types of species, which were initially formed in reduced bimetallic systems and then evolved under storage conditions depend on the reduction temperature used. The presence of silver greatly affects the stability and the mechanism of decomposition/oxidation of reduced copper species. The stability of copper particles possessing a plasmon peak in UV-Vis spectra increases in line with the temperature of reduction $\left(150\right.$ to $\left.450^{\circ} \mathrm{C}\right)$ and they are absent in samples reduced at lower temperatures $\left(25^{\circ} \mathrm{C}\right.$ and $\left.50^{\circ} \mathrm{C}\right)$. In the case of 
an aged monometallic CuCLI-150-A sample reduced at $150{ }^{\circ} \mathrm{C}$, copper nanoparticles are decomposed completely during storage, and their decay leads to the formation of smaller clusters peaking at $475 \mathrm{~nm}$, and $\mathrm{Cu}$ (II) ions. Aged bimetallic samples, reduced at $150{ }^{\circ} \mathrm{C}$, show some decay but after storage a significant intensity of the plasma resonance peak is still preserved, while the $475 \mathrm{~nm}$ feature is present as a shoulder. Samples reduced at $450{ }^{\circ} \mathrm{C}$ demonstrate partial decomposition, accompanied by the formation of the same species peaking at $475 \mathrm{~nm}$. In the case of bimetallic samples reduced at $25^{\circ} \mathrm{C}$ and $50{ }^{\circ} \mathrm{C}$, reduction of silver and the formation of silver clusters and nanoparticles predominate. In the spectra of samples reduced at $25^{\circ} \mathrm{C}$, there is no direct evidence of the presence of reduced copper species. Fresh samples, reduced at $50{ }^{\circ} \mathrm{C}$, have a small amount of nanocopper, but they lose this peak after storage, while some changes in silver nanospecies are observed. Part of the quasicolloidal silver formed in freshly prepared bimetallic samples under the influence of storage conditions is transformed into $\mathrm{Ag}_{8}$ clusters, which indicates a high stability of these nanospecies supported on the natural clinoptilolite matrix. The pattern of decomposition of freshly reduced copper species includes the formation of smaller nanospecies, which can be represented as an intermediate stage preceding the complete oxidation of the $\mathrm{Cu}$ metal to ionic species.

Author Contributions: I.R.-I. and V.P. designed, carried out the experiment and analyzed the data. F.C.-R. and M.G.S. helped to clarify particular aspects of this work. All the authors contributed to prepare the written manuscript as well as to discuss the obtained results. All authors have read and agreed to the published version of the manuscript.

Funding: This research was funded by México, through the grants CONACYT A1-S-33492, UNAMPAPIIT IN115920, and RFBR and CITMA, Russia, in accordance with research Project No. 18-53-34004.

Informed Consent Statement: Not applicable.

Acknowledgments: Thanks for the technical assistance are given to E. Aparicio, I. Gradilla, J. Peralta, E. Flores, J. Mendoza, F. Ruiz and M. Vega. F.C.-R. acknowledges support from COFAA-IPN.

Conflicts of Interest: The authors declare no conflict of interest.

Sample Availability: Samples of the compounds are available from the authors.

\section{References}

1. Jabłnńska, M.; Góra-Marek, K.; Grilc, M.; Bruzzese, P.C.; Poppitz, D.; Pyra, K.; Liebau, M.; Pöppl, A.; Likozar, B.; Gläser, R. Effect of Textural Properties and Presence of Co-Cation on $\mathrm{NH}_{3}$-SCR Activity of Cu-Exchanged ZSM-5. Catalysts 2021, 11, 843. [CrossRef]

2. Wang, L.; Xu, S.; He, S.; Xiao, F.S. Rational construction of metal nanoparticles fixed in zeolite crystals as highly efficient heterogeneous catalysts. Nano Today 2018, 20, 74-83. [CrossRef]

3. Farrusseng, D.; Tuel, A. Perspectives on zeolite-encapsulated metal nanoparticles and their applications in catalysis. New J. Chem. 2016, 40, 3933-3949. [CrossRef]

4. Ramírez-Garza, R.E.; Rodríguez-Iznaga, I.; Simakov, A.; Farías, M.H.; Castillón-Barraza, F.F. Cu-Ag/mordenite catalysts for NO reduction: Effect of silver on catalytic activity and hydrothermal stability. Mater. Res. Bull. 2018, 97, 369-378. [CrossRef]

5. Liu, J.; Liu, X.; Chen, J.; Li, X.; Ma, T.; Zhong, F. Investigation of ZrMnFe/Sepiolite Catalysts on Toluene Degradation in a One-Stage Plasma-Catalysis System. Catalysts 2021, 11, 828. [CrossRef]

6. Mori, K.; Yamashita, H. Design of Colloidal and Supported Metal Nanoparticles: Their Synthesis, Characterization, and Catalytic Application. J. Jpn. Petrol. Inst. 2011, 54,1-14. [CrossRef]

7. Lu, Q.; Qian, W.; Ma, H.; Zhang, H.; Ying, W. Silver-Modified Nano Mordenite for Carbonylation of Dimethyl Ether. Catalysts 2021, 11, 197. [CrossRef]

8. Hessou, E.P.; Bédé, L.A.; Jabraoui, H.; Semmeq, A.; Badawi, M.; Valtchev, V. Adsorption of Toluene and Water over CationicExchanged Y Zeolites: A DFT Exploration. Molecules 2021, 26, 5486. [CrossRef] [PubMed]

9. Zaimee, M.Z.A.; Sarjadi, M.S.; Rahman, M.L. Heavy Metals Removal from Water by Efficient Adsorbents. Water 2021, 13, 2659. [CrossRef]

10. Gupta, A.; Sharma, V.; Sharma, K.; Kumar, V.; Choudhary, S.; Mankotia, P.; Kumar, B.; Mishra, H.; Moulick, A.; Ekielski, A.; et al. A Review of Adsorbents for Heavy Metal Decontamination: Growing Approach to Wastewater Treatment. Materials 2021, 14, 4702. [CrossRef]

11. Liu, J.; Yin, Q.; Zhang, H.; Yan, Y.; Yi, Z. Continuous removal of Cr(VI) and Orange II over a novel Fe ${ }^{0}-\mathrm{NaA}^{\mathrm{A}}$ zeolite membrane catalyst. Sep. Purif. Technol. 2019, 209, 734-740. [CrossRef] 
12. AmilUsmani, M.; Khan, I.; Bhat, A.H.; Pillai, R.S.; Ahmad, N.; Haafiz, M.K.M.; Oves, M. Current Trend in the Application of Nanoparticles for Waste Water Treatment and Purification: A Review. Curr. Org. Synth. 2017, 14, $206-226$.

13. Yoshihara, K.; Nagaoka, N.; Umeno, A.; Sonoda, A.; Obika, H.; Yoshida, Y.; Van Meerbeek, B.; Makita, Y. Antibacterial Effect of Amino Acid-Silver Complex Loaded Montmorillonite Incorporated in Dental Acrylic Resin. Materials 2021, 14, 1442. [CrossRef] [PubMed]

14. Bacakova, L.; Vandrovcova, M.; Kopova, I.; Jirka, I. Applications of zeolites in biotechnology and medicine-A review. Biomater. Sci. 2018, 6, 974-989. [CrossRef] [PubMed]

15. Tan, C.; Han, F.; Zhang, S.; Li, P.; Shang, N. Novel Bio-Based Materials and Applications in Antimicrobial Food Packaging: Recent Advances and Future Trends. Int. J. Mol. Sci. 2021, 22, 9663. [CrossRef] [PubMed]

16. Rodríguez-Méndez, B.G.; López-Callejas, R.; Olguín, M.T.; Valencia-Alvarado, R.; Mercado-Cabrera, A.; Peña-Eguiluz, R.; MuñozCastro, A.E. Growth of Ag particles from Ag-zeolite by pulsed discharges in water and their antibacterial activity. Microporous Mesoporous Mater. 2017, 244, 235-243. [CrossRef]

17. Yao, G.; Lei, J.; Zhang, W.; Yu, C.; Sun, Z.; Zheng, S.; Komarneni, S. Antimicrobial activity of X zeolite exchanged with Cu ${ }^{2+}$ and $\mathrm{Zn}^{2+}$ on Escherichia coli and Staphylococcus aureus. Environ. Sci. Pollut. Res. 2019, 26, 2782-2793. [CrossRef]

18. Paidari, S.; Tahergorabi, R.; Anari, E.S.; Nafchi, A.M.; Zamindar, N.; Goli, M. Migration of Various Nanoparticles into Food Samples: A Review. Foods 2021, 10, 2114. [CrossRef]

19. Morante-Carballo, F.; Montalván-Burbano, N.; Carrión-Mero, P.; Espinoza-Santos, N. Cation Exchange of Natural Zeolites: Worldwide Research. Sustainability 2021, 13, 7751. [CrossRef]

20. Llorens, A.; Lloret, E.; Picouet, P.; Trbojevich, R.; Fernandez, A. Metallic-based micro and nanocomposites in food contact materials and active food packaging. Trends Food Sci. Technol. 2012, 24, 19-29. [CrossRef]

21. Cheng, X.; Huang, L.; Yang, X.; Elzatahry, A.A.; Alghamdi, A.; Deng, Y. Rational design of a stable peroxidase mimic for colorimetric detection of $\mathrm{H}_{2} \mathrm{O}_{2}$ and glucose: A synergistic $\mathrm{CeO}_{2}$ /Zeolite Y nanocomposite. J. Coll. Interf. Sci. 2019, 535, 425-435. [CrossRef] [PubMed]

22. Hovhannisyan, V.; Dong, C.Y.; Chen, S.J. Photodynamic dye adsorption and release performance of natural zeolite. Sci. Rep. 2017, 7, 45503. [CrossRef]

23. Ahari, H.; Anvar, A.A.; Ataeeand, M.; Naeimabadi, M. Employing Nanosilver, Nanocopper, and Nanoclays in Food Packaging Production: A Systematic Review. Coatings 2021, 11, 509. [CrossRef]

24. Wang, L.; Gaudet, J.R.; Li, W.; Weng, D. Migration of Cu species in Cu/SAPO-34 during hydrothermal aging. J. Catal. 2013, 306, 68-77. [CrossRef]

25. Umer, A.; Naveed, S.; Ramzan, N.; Rafique, M.S. Selection of a suitable method for the synthesis of copper nanoparticles. Nano 2012, 7, 1230005-1230023. [CrossRef]

26. Rodríguez-Iznaga, I.; Petranovskii, V.; Castillón-Barraza, F.; Concepción-Rosabal, B. Copper-Silver Bimetallic System on Natural Clinoptilolite: Thermal Reduction of $\mathrm{Cu}^{2+}$ and $\mathrm{Ag}^{+}$Exchanged. J. Nanosci. Nanotechnol. 2011, 11, 5580-5586. [CrossRef]

27. Bajpai, S.K.; Mohan, Y.M.; Bajpai, M.; Tankhiwale, R.; Thomas, V. Synthesis of polymer stabilized silver and gold nanostructures. J. Nanosci. Nanotechnol. 2007, 7, 2994-3010. [CrossRef]

28. Petranovskii, V.; Gurin, V.; Bogdanchikova, N.; Sugi, Y. Controlling copper reducibility in mordenites by varying the $\mathrm{SiO}_{2} / \mathrm{Al}_{2} \mathrm{O}_{3}$ molar ratio. Mater. Lett. 2003, 57, 1781-1785. [CrossRef]

29. Lopez-Bastidas, C.; Smolentseva, E.; Petranovskii, V.; Machorro, R. Plasmon spectra of binary Ag-Cu mixtures supported in Mordenite. In Proceedings of the SPIE Volume 9921, Plasmonics: Design, Materials, Fabrication, Characterization, and Applications XIV, San Diego, CA, USA, 17 September 2016; p. 992130.

30. Rodríguez-Iznaga, I.; Petranovskii, V.; Castillón, F.F.; Farias, M.H. Effect of the Zn(II) on the reduction of Cu(II) in natural clinoptilolita. Opt. Mater. 2006, 29, 105-109. [CrossRef]

31. Petranovskii, V.; Bogdanchikova, N. Reduction of binary silver-copper ion mixture in mordenite: An example of synergetic behavior. Stud. Surf. Sci. Catal. 2002, 141, 569-574.

32. Fiddy, S.; Petranovskii, V.; Ogden, S.; Rodríguez-Iznaga, I. Characterization of Binary Ag-Cu Ion Mixtures in Zeolites: Their Reduction Products and Stability to Air Oxidation. AIP Conf. Proc. 2007, 882, 631-635.

33. Shelyapina, M.G.; Gurgul, J.; Łatka, K.; Sánchez-López, P.; Bogdanov, D.; Kotolevich, Y.; Petranovskii, V.; Fuentes, S. Mechanism of formation of framework $\mathrm{Fe}^{3+}$ in bimetallic Ag-Fe mordenites-Effective catalytic centers for deNO $\mathrm{N}_{\mathrm{x}}$ reaction. Microporous Mesoporous Mater. 2020, 299, 109841. [CrossRef]

34. Ozin, G.A.; Ozkart, S. Zeolates: A coordination chemistry view of metal-ligand bonding in zeolite guest host inclusion-compounds. Chem. Mater. 1992, 4, 511-521. [CrossRef]

35. Kosinov, N.; Liu, C.; Hensen, E.J.M.; Pidko, E.A. Engineering of Transition Metal Catalysts Confined in Zeolites. Chem. Mater. 2018, 30, 3177-3198. [CrossRef]

36. Bogdanchikova, N.; Tuzovskaya, I.; Pestryakov, A.; Susarrey-Arce, A.J. Comparative Study of Formation and Stabilization of Gold and Silver Clusters and Nanoparticles in Mordenites. J. Nanosci. Nanothecnol. 2011, 11, 5476-5482. [CrossRef] [PubMed]

37. Smolentseva, E.; Bogdanchikova, N.; Simakov, A.; Pestryakov, A.; Avalos, M.; Farias, M.H.; Tompos, A.; Gurin, V. Catalytic activity of gold nanoparticles incorporated into modified zeolites. J. Nanosci. Nanotechnol. 2007, 7, 1882-1886. [CrossRef] [PubMed]

38. Tuzovskaya, I.; Lima, E.; Bosch, P.; Bogdanchikova, N.; Pestryakov, A.; Froissart, J. Influence of Cation Nature on Stabilization of Gold Nanospecies in Mordenites. J. Nanosci. Nanothecnol. 2011, 11, 5469-5475. [CrossRef] [PubMed] 
39. Mikhailov, M.; Dergachev, A.; Mishin, I.; Kustov, L.; Lapidus, A. The role played by Ga-Pt nanoparticles in the aromatization of lower alkanes on ZSM-5 zeolites. Russ. J. Phys. Chem. A 2008, 82, 612-618.

40. Mikhailov, M.; Loginova, A.; Kustov, L. The nature of active sites in high-silica zeolites containing platinum and cobalt nanoparticles. Russ. Chem. Bull. 2009, 58, 1598-1601. [CrossRef]

41. Pârvulescu, V.I.; Grange, P.; Delmon, B. Catalytic removal of NO. Catal. Today 1998, 46, 233-326. [CrossRef]

42. Rodríguez-Iznaga, I.; Petranovskii, V.; Rodríguez-Fuentes, G.; Mendoza, C.; Benitez-Aguilar, A. Exchange and reduction of Cu²+ ions in clinoptilolita. J. Coll. Interf. Sci. 2007, 316, 877-886. [CrossRef] [PubMed]

43. Jablonska, M.; Palkovits, R. Copper based catalysts for the selective ammonia oxidation into nitrogen and water vapour-Recent trends and open challenges. Appl. Catal. BEnviron. 2016, 181, 332-351. [CrossRef]

44. Tan, K.S.; Cheong, K.Y. Advances of Ag, Cu, and Ag-Cu alloy nanoparticles synthesized via chemical reduction route. J. Nanopart. Res. 2013, 15, 1537. [CrossRef]

45. Zhukov, Y.M.; Efimov, A.Y.; Shelyapina, M.G.; Petranovskii, V.; Zhizhin, E.V.; Burovikhina, A.; Zvereva, I.A. Effect of preparation method on the valence state and encirclement of copper exchange ions in mordenites. Microporous Mesoporous Mater. 2016, 224, 220-228. [CrossRef]

46. Shelyapina, M.; Zvereva, I.; Yafarova, L.; Bogdanov, D.; Sukharzhevskii, S.; Zhukov, Y.; Petranovskii, V. Thermal analysis and EPR study of copper species in mordenites prepared by conventional and microwave-assisted methods. J. Therm. Anal. Calorim. 2018, 134, 71-79. [CrossRef]

47. Concepción-Rosabal, B.; Rodríguez-Fuentes, G.; Bogdanchikova, N.; Bosch, P.; Avalos, M.; Lara, V.H. Comparative study of natural and synthetic clinoptilolites containing silver in different states. Microporous Mesoporous Mater. 2005, 86, 249-255. [CrossRef]

48. Database of Zeolite Structures. Available online: http:/ / www.iza-structure.org/databases/ (accessed on 31 October 2021).

49. Baerlocher, C.; McCusker, L.B.; Olson, D.H. Atlas of Zeolite Framework Types, 6th ed.; Elsevier: Amsterdam, The Netherlands, 2007; pp. 156-157.

50. Itzel-Hernandez, G.; Hernandez, M.A.; Portillo, R.; Rubio, E.; Petranovskii, V.P.; Pestryakov, A.N. Hierarchical structure of nanoporosity of Mexican natural zeolites of clinoptilolite type. Bull. Tomsk Polytech. Univ. Geo Assets Eng. 2018, 329, $107-117$.

51. Gurin, V.S.; Petranovskii, V.; Hernandez, M.A.; Bogdanchikova, N.E.; Alexeenko, A.A. Silver and copper clusters and small particles stabilized within nanoporous silicate-based materials. Mater. Sci. Engineer. A 2005, 391, 71-76. [CrossRef]

52. Petranovskii, V.; Gurin, V.; Machorro, R. Spectroscopic observation and ab initio simulation of copper clusters in zeolites. Catal Today 2005, 107-108, 892-900. [CrossRef]

53. Gurin, V.S.; Petranovskii, V.; Bogdanchikova, N. Metal clusters and nanoparticles assembled in zeolites: An example of stable materials with controllable particle size. Mater. Sci. Engineer. C 2002, 19, 327-331. [CrossRef]

54. Bogdanchikova, N.; Petranovskii, V.; Machorro, R.; Sugi, Y.; Soto, V.M.; Fuentes, S. Stability of silver clusters in mordenites with different $\mathrm{SiO}_{2} / \mathrm{Al}_{2} \mathrm{O}_{3}$ molar ratio. Appl. Surf. Sci. 1999, 150, 58-64. [CrossRef]

55. Gurin, V.S.; Petranovskii, V.P.; Bogdanchikova, N.E. Silver and copper nanostructures within the erionite regular lattice: Interplay between intra- and extra-crystalline locations. Mater. Sci. Engineer. C 2003, 23, 81-85. [CrossRef]

56. Claridge, S.A.; Castleman, A.W.; Khanna, S.N.; Murray, C.B.; Sen, A.; Weiss, P.S. Cluster-Assembled Materials. ACS NANO 2009, 3, 244-255. [CrossRef]

57. Cui-Ju, F.; Xiao-yan, Z. Structures and Electronic Properties of Cu-N (N $\leq 13)$ Clusters. Commun. Theor. Phys. 2009, 52, 675-680. [CrossRef]

58. Kabir, M.; Mookerjee, A.; Bhattacharya, A.K. Structure and stability of copper clusters: A tight-binding molecular dynamics study. Phys. Rev. A 2004, 69, 043203-043213. [CrossRef]

59. Koitz, R.; Soini, T.M.; Genest, A.; Trickey, S.B.; Rosch, N. Scalable properties of metal clusters: A comparative study of modern exchange-correlation functional. J. Chem. Phys. 2012, 137, 034102-034111. [CrossRef] [PubMed]

60. Wang, L.; Ning, X.J. Isomers of copper clusters obtained by a molecular dynamics model. Int. J. Mod. Phys. B 2005, 19, 2359-2364. [CrossRef]

61. Pestryakov, A.N.; Lunin, V.V.; Devochkin, A.N.; Petrov, L.A.; Bogdanchikova, N.E.; Petranovskii, V. Selective oxidation of alcohols over foam-metal catalysts. Appl. Catal. A 2002, 227, 125-130. [CrossRef]

62. Valodkar, M.; Modi, S.; Pal, A.; Thakore, S. Synthesis and anti-bacterial activity of Cu, Ag and Cu-Ag alloy nanoparticles: A green approach. Mater. Res. Bull. 2011, 46, 384-389. [CrossRef]

63. Momin, T.; Bhowmick, A. Nanoscale alloying: A study in free Cu-Ag bimetallic clusters. J. Alloy. Compd. 2013, 559, 24-33. [CrossRef]

64. Zhang, P.; Xie, Y.; Zhang, W.; Ning, X.; Zhuang, J. Different magic number behaviors in supported metal clusters. J. Nanopart. Res. 2011, 13, 1801-1807. [CrossRef]

65. Pacioni, N.L.; Borsarelli, C.D.; Rey, V.; Veglia, A.V. Synthetic Routes for the Preparation of Silver Nanoparticles. In Silver Nanoparticle Applications. Engineering Materials; Alarcon, E., Griffith, M., Udekwu, K., Eds.; Springer International Publishing Switzerland: Cham, Switzerland, 2015; pp. 13-46. 